\title{
Color and Texture Evaluation in Pasta with Added Cassava Bran and Hydrocolloid
}

\author{
Andrea C. Acosta ${ }^{1}$, Elvis J. Hernandez ${ }^{1}$ and Armando Alvis ${ }^{2 *}$ \\ 'Department of Agro-Industrial Engineering, University of Sucre, Sincelejo - 70001, Colombia; \\ andreina9110@hotmail.com, elvis.hernandez@unisucre.edu.co \\ 2Department of Food Process Engineering, School of Engineering, University of Cordoba, Monteria, Colombia; \\ aalvis@correo.unicordoba.edu.co
}

\begin{abstract}
Objective: To evaluate the effect of cassava bran and hydrocolloids addition on color and texture properties of fiber rich pasta. Methods/Analysis: Wheat semolina pastas were made with 10, 20 and 30\% bran additions, separately enriched with two types of hydrocolloid: xanthan gum (XG) or carboxymethylcellulose (CMC) in $0.5,1$ and $1.5 \%$ concentrations. Color and the textural properties of tensile strength, elasticity and compression were evaluated. Findings: Color analysis showed high luminosity in pastas with $10 \%$ bran and $1.5 \%$ XG. Nonetheless, the most yellow tones were found in pastas with $30 \%$ bran. Textural evaluation of cooked pasta indicated a greater strength and elasticity with lower inclusion of bran and higher concentration of XG. The same behavior was presented in the raw pasta strength. Improvement: Addition of bran decreased textural properties evaluated, while use of hydrocolloids favored them.
\end{abstract}

Keywords: Cassava bran, Color, Hydrocolloids, Pasta, Texture

\section{Introduction}

Cassava (Manihot esculenta Crantz) is a specie of starchy root grown in tropical and subtropical climates around the world due to its excellent capacity to adapt to different climatic conditions and high yields in starch production ${ }^{1}$. The starch production process also generates solid and liquid waste that can become polluting agents if an adequate management and final disposal is not carried out, making necessary to implement cleaner production alternatives in the processes, with an integral use of raw materials and by-products looking for economic and environmental benefit. Cassava bran is one of these residues, a fibrous semisolid material with high moisture content, resulting from separation of starch granules in the sieving stage and containing residual starch not feasible to remove physically ${ }^{2}$. Thanks to fiber content, it can be exploited in the development of food products, such as in functional foods considering that consumers are more concerned every day about health and well-being, looking for food providing benefits beyond traditional nutrients within. They include foods such as breads, beverages and cereals ${ }^{3}$, characterized for being fortified with vitamins and minerals, and recently enriched with dietary fiber. According to the FDA, pastas are thought to be a good vehicle for addition of nutrients. That's why new materials are used

${ }^{*}$ Author for correspondence 
to improve their nutritional value. Dietary fiber content in pastas is low and, given the benefits, it is necessary to add raw materials to increase it. Pasta is considered a food of mass consumption and with high acceptability worldwide, due to low cost and versatility (variety of shapes and sizes) $)^{4}$. Also, it has the advantage of being known for its low glycemic index since it progressively liberates sugars during digestion, and because of the reduction of the glycemic response $\mathrm{e}^{-}$, which is beneficial for the health of people with diabetes.

All these traits in pasta have generated a growing interest in conducting research to improve their nutritional profile ${ }^{6}$, by means of total or partial replacement of wheat semolina with other gluten-free flours, affecting quality and limiting inclusion of these flours in formulation. Therefore, hydrocolloids improving basic properties of food can be used, i.e., the flow behavior (viscosity) and solid characteristics (texture). Hydrocolloids such as xanthan gum (XG), locust bean gum, guar gum, carboxymethylcellulose (CMC) and hydroxypropylmethylcellulose (HPMC) are used, among others, to mimic viscoelastic properties of gluten and give firmness; thus, improving texture characteristics of pasta in which wheat semolina has been partially or totally replaced, thanks to water binding capacity of hydrocolloids ${ }^{\mathrm{z}}$.

Acceptance of pasta by consumers is determined by its quality traits, in which the typical yellow color and textural properties of raw and cooked pastapredominate ${ }^{8}$. They can be affected by type of raw material used in the elaboration. Therefore, the objective of this work was to evaluate the color and texture properties of fiber-rich food pastaby adding cassava bran and supplemented with hydrocolloids.

\section{Methodology}

\subsection{Raw Material}

Commercial wheat semolina was used, supplied by the Harinera Pardo S.A Company. Hydrocolloids (Xanthan Gum -XG and Carboxymethylcellulose-CMC) were supplied by Bell Chem International S.A. The bran used was obtained from the extraction process of native cassava starch from Almidones de Sucre S.A.S. company, located in the municipality of Sincelejo - Sucre - Colombia. The bran was subject to a $10 \mathrm{psi}$ pressing process to decrease water content, drying with warm air at $55^{\circ} \mathrm{C}$ for 24 hours to an $11 \%$ final humidity and eventually to a grinding and sieving process to bring it to the same particle size as the semolina ( $\leq$ mesh 40 ) to obtain uniformity in the finished product ${ }^{9}$.

\subsection{Pasta Preparation}

Mixtures of wheat semolina were prepared by adding cassava bran in 10, 20 and $30 \%$ ratios. $1 \%$ salt in flour base was added to these mixtures. Hydrocolloids were dissolved in water at $50^{\circ} \mathrm{C}^{5}$ and subsequently added to the flours' mixture previously prepared. A mixing and kneading process was carried out for $10 \mathrm{~min}$ to achieve good hydration. Obtained mass was extruded as fettuccine type pasta ( $4 \mathrm{~mm}$ diameter). Finally, a drying process was carried out at $70^{\circ} \mathrm{C}$ up to a 10 and $11.5 \%$ final humidity ${ }^{5}$.

\subsection{Color Analysis}

To determine color, a Colorflex EZ 45 colorimeter (HunterLab ${ }^{\circ}$ ) was used, measuring instrumental parameters, by means of CIElab system; where color space is a Cartesian coordinate system defined by three rectangular coordinates $L^{\star}$ (brightness or clarity) from white $(\mathrm{L}=$ 100) to black ( $\mathrm{L}=0), a^{\star}$ (red-green), $b^{\star}$ (yellow -blue) of dimensionless magnitudes. Color study of wheat semolina, cassava bran and pasta obtained was carried out. The study of color of pastas was carried out in cooked pasta until optimal cooking time, which were left to rest $5 \mathrm{~min}$ after cooking up to reaching room temperature (Foschia et al., 2015). Three measurements with their respective average were taken.

\subsection{Texture Analysis}

Texturometer model TA.TX2i ${ }^{\circledR}$. plus, Stable Micro System equipped with a $5 \mathrm{~kg}$ charge cell was used by the 16.50 AACC (2000) method. The equipment was coupled to the Texture Exponent 32 software. The following tests were performed: 
Tensile strength and elasticity in cooked pastas: For these analyzes, the A/SPR sensor was used. Pastas were cooked with water at boiling temperature for $5 \mathrm{~min}$ (optimal cooking time), rinsed with $100 \mathrm{ml}$ distilled water and allowed to stand for $10 \mathrm{~min}$ until room temperature was reached. Sample was placed between friction rollers by rolling 2 or 3 times to avoid slipping and ensure that the rupture occurred along the wide part of the sample. For carrying out the test, some adjustments were considered: speed before test: $3 \mathrm{~mm} / \mathrm{s}$; test speed: $3 \mathrm{~mm} / \mathrm{s}$, speed after test: $5 \mathrm{~mm} / \mathrm{s}$, initial distance: $10 \mathrm{~mm}$; final distance: 100 $\mathrm{mm}$; type of shot: $5 \mathrm{~g}$ auto; data acquisition speed: 200pps. Results were expressed as maximum rupture resistance $(\mathrm{N})^{10-11}$.

Raw Pasta Compression characteristics: This texture characteristic determines the breaking or rupture strength of the long pasta using an A/SFR tension probe. A $20 \mathrm{~cm}$ long raw pasta sample was used, placed between upper and lower supports perfectly aligned with each other to obtain a correct vertical support of the sample. By applying the force of the head on the pulp wire, compression was started, and it was flexed until broken. Results were expressed as rupture force $(\mathrm{N})$. To carry out the test, the following parameters were considered: pre-test speed: $0.5 \mathrm{~mm} / \mathrm{s}$, test speed: $2.5 \mathrm{~mm} / \mathrm{s}$, post-test speed: $10 \mathrm{~mm} / \mathrm{s}$, data acquisition speed: 400pps, trigger type: Auto-15g, distance from head to sample: $50 \mathrm{~mm}$ (Ref. A/SFR, Stable Micro System) $\underline{12}$.

\section{Experimental Design}

A factorial experiment was carried out under a completely randomized design (CRD). Which in the following factors were considered: Wheat semolina substitution by cassava bran (10, 20 and 30\%), hydrocolloid type (XG, $\mathrm{CMC}$ ) and hydrocolloid concentration (0.5, 1 and 1, 5\%). Results obtained from the experimental part were analyzed by means of an ANOVA and for the comparison of means, the Tukey multiple range test was used at a $5 \%$ significance level.

\section{Results and Discussion}

\subsection{Color of Cassava Bran and Wheat Semolina}

Cassava bran showed a high luminosity and tendencies towards reddish and yellow tones, as evidenced by values found in color attributes $L^{\star}=88.03 \pm 0.24, a^{\star}=2.91$ \pm 0.08 and $b^{\star}=16.10 \pm 0.24$ respectively. This could be due to fiber content present in the bran. In integral flours, darkening is a common color attribute, since components such as fiber accumulate in the grain outer part; and to a greater polishing, less removal in peripheral layers causing greater darkening ${ }^{13}$. Equivalent results were reported by $^{1}$ who evaluated color for two samples of cassava bran taken from two regions with different environmental conditions for cassava cultivation, being very similar in terms of luminosity $(83,79)$ and tendency towards red and yellow color shown by the values in attributes of $\mathrm{a}^{*}$ and $\mathrm{b}^{*}$ respectively.

Color analysis for wheat semolina showed values of $\mathrm{L}^{*}$ $=86.48 \pm 0.43, a^{*}=1.42 \pm 0.12$ and $b^{*}=18 \pm 0.20$. These results agree with those reported by ${ }^{14}$, who found $b^{*}$ values between 18.6 and 22.6, indicating the yellow color in the sample and $L^{\star}$ values (brightness or luminosity) between 86.6 and 87 . Differences in the color attributes of wheat semolina can be caused by genotype and crop environmental conditions. Color characteristics of wheat semolina determine the color of pasta and is considered an attribute of quality relevant to the consumer. In fact, the bright yellow color in semolina is very important and is mainly due to carotenoid pigments, although it can be affected by the amount of ash included ${ }^{14}$.

\subsection{Pasta Color}

Results obtained for luminosity parameter $L^{\star}$ are shown in Table 1. In general, values for $L^{*}$ were high since they ranged between 60 and 70. Equivalent results were reported by 15 ( 59 to 69 ) in pastes made with $2 \beta$-glucan concentrates. Nonetheless, results found are above those reported by ${ }^{16}$ (29.6 to 32.30) for gluten-free pastas made from high-protein flours (soybean meal, channa 
Table 1. Parameter $L^{\star}$ of the pasta with different bran amount and hydrocolloid amount

\begin{tabular}{|c|c|c|c|}
\hline \multirow{2}{*}{ Hydrocolloid (\%) } & 10 & 20 & 30 \\
\cline { 2 - 4 } & \multicolumn{3}{|c|}{ XGan amount (\%) } \\
\hline $\mathbf{0 , 5}$ & $69,57 \pm 0,53^{\mathrm{aA}}$ & $66,92 \pm 0,37^{\mathrm{aB}}$ & $62,96 \pm 0,63^{\mathrm{aC}}$ \\
\hline $\mathbf{1}$ & $70,46 \pm 1,12^{\mathrm{aA}}$ & $66,62 \pm 0,28^{\mathrm{aB}}$ & $60,71 \pm 0,09^{\mathrm{bC}}$ \\
\hline $\mathbf{1 , 5}$ & $70,61 \pm 1,01^{\mathrm{aA}}$ & $66,43 \pm 0,58^{\mathrm{aB}}$ & $61,01 \pm 0,69^{\mathrm{bC}}$ \\
\hline $\mathbf{0 , 5}$ & & $\mathbf{C M C}$ & $59,25 \pm 1,25^{\mathrm{cC}}$ \\
\hline $\mathbf{1}$ & $68,56 \pm 0,9^{\mathrm{aA}}$ & $64,77 \pm 0,73^{\mathrm{aB}}$ & $60,61 \pm 0,6^{\mathrm{bB}}$ \\
\hline $\mathbf{1 , 5}$ & $66,86 \pm 0,81^{\mathrm{bA}}$ & $60,24 \pm 0,75^{\mathrm{cB}}$ & $62,91 \pm 0,59^{\mathrm{aB}}$ \\
\hline
\end{tabular}

Means with different letters in columns (lowercase, indicate comparisons among hydrocolloid amount for each quantity of bran and hydrocolloid type) and rows (uppercase, indicate comparisons among quantities of bran for each quantity and hydrocolloid type) indicate statistically significant difference according to the Tukey test $(\mathrm{p}<0.05)$.

flour, sorghum flour and whey protein concentrate) and supplemented with hydrocolloids (XG, guar gum and hydroxypropyl methylcellulose); possibly due to low $\mathrm{L}^{*}$ values of these gluten-free flours compared to the luminosity of grits. On the other hand, results found are lower than those reported by ${ }^{11}$ for pastas made with dietary fibers (oat bran, psyllium fiber, Glucagel and inulin) ranged between 92 and 97, possibly due to type of supplement used in the pastas preparation.

Analysis of variance shows that factors: bran amount, hydrocolloid type, hydrocolloid amount and the interaction among these three factors were significant $(\mathrm{p} \leq 0.05)$. In pastas made with XG or CMC at any concentration, an increase in the bran amount causes a decrease in $L^{*}$ value, possibly due to the higher ash content present in the cassava bran $(2.17 \%)$ compared to the ash present in wheat semolina $(0.5 \%)^{\frac{17}{1}}$, causing browning in pastas, a typical trend of whole wheat flours ${ }^{13}$. Equivalent results were found in pasta with pumpkin flour inclusions ${ }^{8}$.

In pastas elaborated with the cassava bran amounts studied, it is shown that when using XG, higher $L^{\star}$ values are obtained than with $\mathrm{CMC}$ at any concentration, since it is typical of XG to give transparency and brightness to the food, while CMC is characterized by opacity. This behavior could be due to natural color of biopolymers, which produces an effect of clarity in some foods, especially at high concentrations $s^{18}$. These results agree with those reported by ${ }^{\frac{16}{6}}$, who found that pastas added with XG presented values of $L^{*}$ higher than those found in pastas added with hydroxypropyl methylcellulose. The same 
Table 2. Parameter $\mathrm{a}^{\star}$ of pasta with different bran amount and hydrocolloid amount

\begin{tabular}{|c|c|c|c|}
\hline \multirow{2}{*}{ Hydrocolloid (\%) } & $\mathbf{3}$ & \multicolumn{3}{|c|}{ Bran (\%) } \\
\cline { 2 - 4 } & \multicolumn{3}{|c|}{ XG } \\
\hline $\mathbf{0 , 5}$ & $2,59 \pm 0,33^{\mathrm{aC}}$ & $3,77 \pm 0,33^{\mathrm{aB}}$ & $4,86 \pm 0,19^{\mathrm{bA}}$ \\
\hline $\mathbf{1}$ & $2,72 \pm 0,18^{\mathrm{aC}}$ & $3,77 \pm 0,26^{\mathrm{aB}}$ & $5,51 \pm 0,10^{\mathrm{aA}}$ \\
\hline $\mathbf{1 , 5}$ & $2,78 \pm 0,54^{\mathrm{aC}}$ & $3,87 \pm 0,24^{\mathrm{aB}}$ & $5,26 \pm 0,02^{\mathrm{abA}}$ \\
\hline \multirow{2}{*}{$\mathbf{0 , 5}$} & $2,19 \pm 0,26^{\mathrm{bC}}$ & $4,44 \pm 0,22^{\mathrm{aB}}$ & $5,28 \pm 0,14^{\mathrm{aA}}$ \\
\hline $\mathbf{1}$ & $2,22 \pm 0,31^{\mathrm{bB}}$ & $4,30 \pm 0,06^{\mathrm{aA}}$ & $4,26 \pm 0,35^{\mathrm{bA}}$ \\
\hline $\mathbf{1 , 5}$ & $2,90 \pm 0,10^{\mathrm{aB}}$ & $4,13 \pm 0,11^{\mathrm{aA}}$ & $4,08 \pm 0,28^{\mathrm{bA}}$ \\
\hline
\end{tabular}

Means with different letters in columns (lowercase, indicate comparisons among hydrocolloid amount for each quantity of bran and hydrocolloid type) and rows (uppercase, indicate comparisons among quantities of bran for each quantity and hydrocolloid type) indicate statistically significant difference according to the Tukey test $(\mathrm{p}<0.05)$.

behavior was found in the production of flat bread without gluten with hydrocolloids, observing that the bread with XG have luminosity values higher than those made with CMC in all concentrations used; both, in the crumb and in the crust of the loaves, showing that XG has greater influence on $L^{*}$ and improves this property ${ }^{19}$.

Positive $\mathrm{a}^{*}$ values (Table 2 ), indicated a visual position regarding the red color and were in the 2.1 to 5.51 range. Reddening may be associated with the Maillard reaction development, since non-enzymatic browning related to this reaction easily occurs during the pasta drying, especially at high and very high temperatures $\frac{17}{}$, and it may also be associated with contamination with bran ${ }^{20}$.

Analysis of variance shows that factors: bran amount, hydrocolloid type and the interaction bran amount * hydrocolloid type ${ }^{\star}$ hydrocolloid amount were significant $(\mathrm{p} \leq 0.05)$. In pastas made with XG or CMC at any concentration, an increase in the bran amount causes an increase in the $\mathrm{a}^{*}$ value, possibly due to the tendency of cassava bran towards the red tonality (2.91), greater than in the wheat semolina $(1,42)$. Similarly ${ }^{20}$ reported an increase in $\mathrm{a}^{*}$ index with the increase of raw amaranth flour in the pasta formulation. A similar behavior was reported for pasta fortified with pumpkin flour ${ }^{8}$. It is to be considered that presence of a darker color in the cassava substitution with cassava bran compared to those made from only wheat semolina $\left(a^{*}=-3.6\right)$ is a negative factor in their appearance. However, some consumers can accept them, given their greater nutritional value; brown color in pastas may be related to an antioxidant potential, which can be attributed to brown melanoidins ${ }^{20}$. 
Table 3. Parameter $b^{*}$ of the pasta with different bran amount and hydrocolloid type

\begin{tabular}{|c|c|c|c|}
\hline \multirow{2}{*}{ Hydrocolloidtype } & \multicolumn{3}{|c|}{ Bran (\%) } \\
\cline { 2 - 4 } & 10 & 20 & 30 \\
\hline GX & $16,39 \pm 0,64^{\mathrm{aC}}$ & $17,88 \pm 0,29^{\mathrm{aB}}$ & $18,85 \pm 0,3^{\mathrm{aA}}$ \\
\hline CMC & $15,72 \pm 0,71^{\mathrm{bC}}$ & $17,9 \pm 0,42^{\mathrm{aA}}$ & $17,14 \pm 0,84^{\mathrm{bB}}$ \\
\hline
\end{tabular}

Averages with different letters in columns (lowercase, indicate comparisons among the hydrocolloid type for each quantity of bran) and rows (uppercase, indicate comparisons among quantities of bran for each hydrocolloid type) indicate a statistically significant difference according to the Tukey test (p. <0.05).

Table 4. Parameter $\mathrm{b}^{\star}$ of the pasta with different bran amount and hydrocolloid amount

\begin{tabular}{|c|c|c|c|}
\hline \multirow{2}{*}{ Hydrocolloid (\%) } & \multicolumn{3}{|c|}{ Bran (\%) } \\
\cline { 2 - 4 } & 10 & 20 & 30 \\
\hline 0,5 & $15,62 \pm 0,59^{\mathrm{bB}}$ & $18,13 \pm 0,34^{\mathrm{aA}}$ & $18,59 \pm 0,46^{\mathrm{aA}}$ \\
\hline 1 & $16,052 \pm 0,58^{\mathrm{abB}}$ & $17,89 \pm 0,31^{\mathrm{aA}}$ & $17,69 \pm 0,25^{\mathrm{bA}}$ \\
\hline 1,5 & $16,49 \pm 0,57^{\mathrm{aB}}$ & $17,64 \pm 0,17^{\mathrm{aA}}$ & $17,68 \pm 0,36^{\mathrm{bA}}$ \\
\hline
\end{tabular}

Meanswith differentletters in columns (lowercase, indicate comparisons amonghydrocolloid amount for each quantity of bran) and rows (uppercase, indicate comparisons between quantities of bran for each hydrocolloid amount) indicate statistically significant difference according to the Tukey test (p. <0.05).

On the other hand, differences were found between XG and CMC for each hydrocolloid amount and amount of added bran, observing that in pastas made with $10 \%$ cassava bran, it was found that when using XG at $1 \%$, $\mathrm{a}^{*}$ value was greater than when using CMC; a similar trend was observed in pastas made with $30 \%$ cassava bran and $1 \%$ and $1.5 \%$ XG. These results agree with those from Susanna and Prabhasankar (2013), who, when making gluten-free pasta with protein meals and added with hydrocolloids, found that treatments with GX presented values for $\mathrm{a}^{*}$ higher than with hydroxypropyl methylcel- lulose, but lower than those found with guar gum and without additives. Nonetheless, for pastas made with $20 \%$ cassava bran, CMC presented $\mathrm{a}^{*}$ values higher than the GX in of $0.5 \%$ and $1 \%$ concentrations, this behavior was also evidenced by ${ }^{19}$ when preparing flat bread with XG or CMC, where higher $a^{*}$ values in the bread crust with CMC were observed.

As for the yellow-blue chromaticity $\left(b^{*}\right)$, values were found between 15.6 and 18.8 (Tables 3-5), being in the yellow tone. The yellowish color of the pasta is affected by degradation of carotenoid pigments of the xanthophyll 
Table 5. Parameter $\mathrm{b} *$ of pastas with different type and hydrocolloid amount

\begin{tabular}{|c|c|c|}
\hline \multirow{2}{*}{ Hydrocolloid (\%) } & \multicolumn{2}{|c|}{ Hydrocolloidtype } \\
\cline { 2 - 3 } & XG & CMC \\
\hline 0,5 & $17,67 \pm 0,45^{\mathrm{aA}}$ & $17,23 \pm 0,48^{\mathrm{aB}}$ \\
\hline 1 & $17,83 \pm 0,26^{\mathrm{aA}}$ & $16,6 \pm 0,51^{\mathrm{bB}}$ \\
\hline 1,5 & $17,62 \pm 0,4^{\mathrm{aA}}$ & $16,92 \pm 0,33^{\mathrm{abB}}$ \\
\hline
\end{tabular}

Averages with different letters in columns (lowercase, indicate comparisons among hydrocolloid amount for hydrocolloid type) and rows (uppercase, indicate comparisons among hydrocolloid type for each hydrocolloid amount) indicate statistically significant difference according to the Tukey test $(\mathrm{p}<0.05)$.

type in the semolina, caused by oxidative enzymes, such as lipoxygenases, peroxidases and polyphenol oxidases and the manufacturing process ${ }^{8}$. Mixing and kneading processes in the preparation of the pasta lead to incorporation of water and oxygen in the dough, which promotes oxidation of poly unsaturated fatty acids mediated by polyphenol oxidase, which in turn favor oxidation of carotenoids $^{21}$. Equivalent results regarding the yellow color of pasta were reported by ${ }^{\underline{8}}$ when making pastas including the durian seed flour. Differences that can occur in the $b^{*}$ shade are possibly due to the different raw materials used as substitution of the wheat semolina in the preparation of the pasta or it can also be due to variation in the quantity of carotenoid pigments according to wheat cultivars used to obtain semolina. Generally, consumers prefer pasta with a bright yellow color ${ }^{17}$. Analysis of variance shows that factors: quantity of bran and hydrocolloid type, and the interactions bran amount * hydrocolloid type, bran amount ${ }^{*}$ hydrocolloid type, and hydrocolloid type ${ }^{\star}$ hydrocolloid amount were significant $(\mathrm{p} \leq 0.05)$.

In Table 3, results of the parameter $b^{*}$ are shown, for the interaction of the quantity of bran ${ }^{\star}$ hydrocolloid type factors. It was found that in pastas made with $10 \%$ and $30 \%$ bran, higher $b^{\star}$ values were obtained when using
XG compared to CMC. In addition, when using GX, an increase in the bran amount causes an increase in the of $\mathrm{b}^{*}$ values. Similarly ${ }^{20}$ reported that the $b^{*}$ value increased as the percentage of raw amaranth flour increased, which was attributed to the amount of carotenoid pigments and enzymatic reactions.

In Table 5, type hydrocolloid * hydrocolloid amount interaction is presented. Use of CMC at concentrations of $1 \%$ and $1.5 \%$ caused the lowest $b^{\star}$ values in the processed pastas compared to XG.

Generally, color in pastas depends on type of wheat used and is determined by presence of carotenoid pigments - yellow color being desirable. Differences observed in the colors of pastas made with respect to the cited authors can be associated to differences in the quantities and qualities of pigments present in the raw materials used in the different formulations?

\subsection{Pasta Texture}

Pasta made with cassava bran and supplemented with hydrocolloids was texturally characterized with the following parameters: for pasta cooked by tension characteristics (maximum rupture strength and elasticity) and for raw pasta by compression characteristics as maximum rupture strength. 
Table 6. Maximum rupture strength $(\mathrm{N})$ of pasta with different bran amount and hydrocolloid type

\begin{tabular}{|c|c|c|c|}
\hline \multirow{2}{*}{ Hydrocolloidtype } & \multicolumn{3}{|c|}{ Bran (\%) } \\
\cline { 2 - 4 } & 10 & 20 & 30 \\
\hline XG & $0,328 \pm 0,05^{\mathrm{aA}}$ & $0,247 \pm 0,028^{\mathrm{aB}}$ & $0,155 \pm 0,029^{\mathrm{aC}}$ \\
\hline CMC & $0,238 \pm 0,02^{\mathrm{bA}}$ & $0,245 \pm 0,051^{\mathrm{aA}}$ & $0,178 \pm 0,035^{\mathrm{aB}}$ \\
\hline
\end{tabular}

Mean with different letters in columns (lowercase, indicate comparisons among the hydrocolloid type for each quantity of bran) and rows (uppercase, indicate comparisons among quantities of bran for each hydrocolloid type) indicate a statistically significant difference according to the Tukey test (p. <0.05).

\subsubsection{Tensile Strength and Elasticity of Cooked Pasta}

Results obtained in the tensile strength of cooked pasta ranged between 0.13 and $0.32 \mathrm{~N}$. susceptibility to breakage or stress to spaghetti rupture is associated with residual deformations, depending on presence of structuring agents and their concentrations. In addition, the breaking properties of a product depend on the properties of the matrix and presence of defects 22 . Analysis of variance shows that the factors: bran amount, hydrocolloid type and hydrocolloid amount were significant $(p \leq 0,05)$ and the interactions bran amount ${ }^{*}$ hydrocolloid type, bran amount ${ }^{*}$ hydrocolloid amount and hydrocolloid type * hydrocolloid amount were significant $(\mathrm{p} \leq 0.05)$.

In Table 6, the results of the interaction bran amount * hydrocolloid type are shown. When using XG or CMC, an increase in the bran amount (10\% to $30 \%)$ causes a decrease in the maximum rupture resistance $(\mathrm{N})$, this behavior is associated with the characteristic structural changes ocurring in the network of proteins by adding other flours in the preparation of pastas ${ }^{10}$, which generates the disruption of the protein network by the presence of fibers, affecting the texture of the surface when starch

Table 7. Maximum rupture strength $(\mathrm{N})$ of pasta with different bran amount and hydrocolloid amount

\begin{tabular}{|c|c|c|c|}
\hline \multirow{2}{*}{$\begin{array}{c}\text { Hydrocolloid } \\
(\%)\end{array}$} & 10 & 20 & \multicolumn{3}{|c|}{ Bran (\%) } \\
\cline { 2 - 4 } & $0,236 \pm 0,01^{\mathrm{bA}}$ & $0,236 \pm 0,02^{\mathrm{abA}}$ & $0,137 \pm 0,03^{\mathrm{bB}}$ \\
\hline 0,5 & $0,304 \pm 0,01^{\mathrm{aA}}$ & $0,230 \pm 0,02^{\mathrm{bB}}$ & $0,177 \pm 0,02^{\mathrm{aC}}$ \\
\hline 1 & $0,309 \pm 0,02^{\mathrm{aA}}$ & $0,272 \pm 0,05^{\mathrm{aA}}$ & $0,185 \pm 0,02^{\mathrm{aB}}$ \\
\hline 1,5 & & & \multicolumn{3}{|c|}{} \\
\hline
\end{tabular}

Mean with different letters in columns (lowercase, indicate comparisons among hydrocolloid amount for each quantity of bran) and rows (uppercase, indicate comparisons among quantities of bran for each hydrocolloid amount) indicate statistically significant difference according to the Tukey test (p. <0.05). 
Table 8. Maximum rupture resistance $(\mathrm{N})$ of pastas with different type and hydrocolloid amount

\begin{tabular}{|c|c|c|}
\hline \multirow{2}{*}{ Hydrocolloid (\%) } & \multicolumn{2}{|c|}{ Hydrocolloidtype } \\
\cline { 2 - 3 } & XG & CMC \\
\hline 0,5 & $0,203 \pm 0,002^{\mathrm{bA}}$ & $0,202 \pm 0,026^{\mathrm{bA}}$ \\
\hline 1 & $0,261 \pm 0,013^{\mathrm{aA}}$ & $0,212 \pm 0,017^{\mathrm{bB}}$ \\
\hline 1,5 & $0,265 \pm 0,022^{\mathrm{aA}}$ & $0,246 \pm 0,039^{\mathrm{aA}}$ \\
\hline
\end{tabular}

Means with different letters in columns (lowercase, indicate comparisons between hydrocolloid amount for hydrocolloid type) and rows (uppercase, indicate comparisons between hydrocolloid type for each hydrocolloid amount) indicate statistically significant difference according to the Tukey test $(\mathrm{p}<0.05)$.

granules disintegrate by cooking in water ${ }^{16}$. Given the partially available water for the development of the gluhigh affinity of the fiber for water, it probably leaves only ten network, resulting in a paste of lower hardness. When

Table 9. Elasticity of cooked pasta with different bran amount and hydrocolloid amount

\begin{tabular}{|c|c|c|c|}
\hline \multirow{2}{*}{ Hydrocolloid (\%) } & 10 & 20 & 30 \\
\cline { 2 - 4 } & \multicolumn{3}{|c|}{ Bran amount $(\%)$} \\
\hline $\mathbf{0 , 5}$ & $13,7 \pm 1,05^{\mathrm{cA}}$ & $8,67 \pm 0,84^{\mathrm{bB}}$ & $9,98 \pm 0,78^{\mathrm{bB}}$ \\
\hline $\mathbf{1}$ & $34,72 \pm 0,71^{\mathrm{bA}}$ & $8,82 \pm 0,17^{\mathrm{bB}}$ & $8,75 \pm 0,26^{\mathrm{bB}}$ \\
\hline $\mathbf{1 , 5}$ & $38,34 \pm 0,95^{\mathrm{aA}}$ & $12,29 \pm 0,26^{\mathrm{aC}}$ & $14,29 \pm 0,28^{\mathrm{aB}}$ \\
\hline & & $\mathbf{C M C}$ & \\
\hline $\mathbf{0 , 5}$ & $12,33 \pm 1,23^{\mathrm{cA}}$ & $4,97 \pm 0,78^{\mathrm{cB}}$ & $5,24 \pm 0,48^{\mathrm{aB}}$ \\
\hline $\mathbf{1}$ & $14,47 \pm 0,81^{\mathrm{bA}}$ & $6,93 \pm 0,9^{\mathrm{bB}}$ & $6,18 \pm 0,73^{\mathrm{aB}}$ \\
\hline $\mathbf{1 , 5}$ & $16,22 \pm 1,16^{\mathrm{aA}}$ & $12,07 \pm 0,89^{\mathrm{aB}}$ & $6,81 \pm 0,8^{\mathrm{aC}}$ \\
\hline
\end{tabular}

Means with different letters in columns (lowercase, indicate comparisons among hydrocolloid amount for each quantity of bran and hydrocolloid type) and rows (uppercase, indicate comparisons among quantities of bran for each quantity and hydrocolloid type) indicate statistically significant difference according to the Tukey test $(\mathrm{p}<0.05)$. 
the formation of this network is delayed, starch granules swell highly and rapidly, being susceptible to rupture and reducing the firmness of pastes ${ }^{23}$. Equivalent results were reported by 11 in pasta with partial substitution of semolina by different fiber sources (oat bran, Physillium, glucagel, insulins), which oscillated between 0.16 to $0.40 \mathrm{~N}$, being close to those found in this study. They observed a significant decrease in the strength of pastas at higher fiber content. On the other hand $\frac{17}{}$ when performing a tensile test, found that energy of rupture in pastas with $35 \%$ of peas was lower than that of durum wheat pasta, which they attributed to the inclusion of fiber fractions that probably cause the appearance of discontinuities or cracks inside the pasta, which weakens its structure; this parameter is associated with the strength to breakage of pasta.

In Table 7, the interaction bran amount ${ }^{*}$ hydrocolloid amount is shown. To any bran amount used, an increase in the hydrocolloid amount (from $0.5 \%$ to $1.5 \%$ ) causes a greater resistance to the maximum breakage of the pastas, which can be associated with the high capacity of water absorption of hydrocolloids, improving its firmness ${ }^{24}$, which may be related to rupture strength and fragility of a product; and also, hydrocolloids are incorporated into the protein matrix, becoming an integral part of the pasta structure and encapsulating the starch granules that seem to stabilize and possibly increase the firmness of pasta $\underline{25}$. A similar behavior was observed in pasta with egg albumin, protein concentrates of rice bran, soy protein and whey proteins as protein supplements ${ }^{26}$ and in gluten-free pastas supplemented with XG and guar gum in $0 \%, 1 \%$ and $2 \%$ concentrations, where they observed that firmness increased with addition of hydrocolloids, thus improving the starch network. Since pastas without hydrocolloids disintegrated during cooking, these hydrocolloids promoted the association of granules of starch at high temperature, involved with the improvement in texture.

The interaction type hydrocolloid * hydrocolloid amount for the maximum rupture strength of the pastes are detailed in Table 8. When using XG or CMC an increase in their amount (from $0.5 \%$ to $1.5 \%$ ) causes an increase in the resistance to maximum rupture, finding the highest values when using $1.5 \%$. In addition, greater resistance to maximum breakage was observed with $1 \%$ XG compared to CMC at the same concentration. This behavior can be attributed to the fact that GX has a greater water absorption capacity than $\mathrm{CMC}$, which favors more resistance in the pastas ${ }^{24}$. A similar behavior was found in pastas added with XG and guar gum, where greater firmness was observed in pastas containing $\mathrm{XG}^{27}$.

In Table 9, results obtained for the elasticity of the pastas are shown, which ranged between 4.97 and $38.34 \mathrm{~mm}$. ANOVA shows that factors: bran amount, hydrocolloid type and hydrocolloid amount and their interaction significantly affected the elasticity variable in cooked pasta.

In pastas made with XG or CMC at any concentration, an increase in the bran amount (from 10\% to 30\%) causes decrease in elasticity, observing the higher elasticity in those made with $10 \%$ cassava bran, that, the lower the inclusion of bran in the formulation, the structure is better preserved thanks to the fact that the greater amount of gluten in the semolina gives pasta strands a more solid network. It is possible that structural changes occur in the protein network due to the addition of other flours with high fiber content different from wheat semolina, because this generates a disruptive behavior of network during the formation of the pasta matrix ${ }^{10}$; affected by the type and amount of fiber added $\frac{25}{}$. In $\frac{10}{}$, reported that, when increasing the inclusion of pea flour in pasta, the elasticity decreased, going from 26.98 to $18.3 \mathrm{~mm}$ for pasta with 20 and $40 \%$ of this flour respectively. Nonetheless, this behavior differs from that reported by ${ }^{28}$ in pasta with semolina substitution by diverse levels of meat emulsion, where the elasticity showed an increase with the addition of the emulsion, which is possibly since the meat protein improves the gluten network.

In addition, in pastas made with XG or $\mathrm{CMC}$ and the different amounts of cassava bran, an increase in the amount added of the hydrocolloid (from $0.5 \%$ to $1.5 \%$ ) causes an increase in elasticity ${ }^{23}$ reported an increase in the extensibility of masses for gluten-free pastas made from glutinous rice thanks to the addition of XG in concentrations of $1 \%, 3 \%$ and $5 \%$ showing that this gum 
improves the interactions between the gelatinized granules, but, when adding $7 \%$ of gum there was a decrease in the extensibility associated with the fact that the excess of gum could compete with the starch for water. However ${ }^{29}$ reported that pastas with broccoli powder and added with hydrocolloids had less extensibility with respect to the control without hydrocolloids.

In pastas elaborated with the amounts of cassava bran studied, it is shown that when using XG, greater elasticity is obtained than with CMC at any concentration ${ }^{29}$ reported that the type and concentration of hydrocolloid was a less influential factor in its extensibility.

\subsubsection{Compression Characteristics of Raw Pasta}

Results found for the rupture strength in raw pasta ranged from 0.27 to $0.52 \mathrm{~N}$, being close to those reported by $^{12}$ for vermicelli-type commercial pasta, which determined an average breaking strength of $0.60 \mathrm{~N}(61.63 \mathrm{~g})$. The differences in the mechanical properties of dry pasta are related to the chemical characteristics and the par-

Table 10. Rupture strength $(\mathrm{N})$ of the pasta with different bran amount and hydrocolloid type

\begin{tabular}{|c|c|c|c|}
\hline \multirow{2}{*}{ Hydrocolloidtype } & \multicolumn{3}{|c|}{ Bran Amount (\%) } \\
\cline { 2 - 4 } & 10 & 20 & 30 \\
\hline XG & $0,526 \pm 0,005^{\mathrm{aA}}$ & $0,34 \pm 0,008^{\mathrm{aB}}$ & $0,277 \pm 0,013^{\mathrm{bC}}$ \\
\hline CMC & $0,41 \pm 0,097^{\mathrm{bA}}$ & $0,31 \pm 0,042^{\mathrm{aB}}$ & $0,337 \pm 0,049^{\mathrm{aB}}$ \\
\hline
\end{tabular}

Averages with different letters in columns (lowercase, indicate comparisons among the hydrocolloid type for each quantity of bran) and rows (uppercase, indicate comparisons among quantities of bran for each hydrocolloid type) indicate a statistically significant difference according to the Tukey test (p. <0.05).

Table 11. Rupture strength (N) of pastas with different type and hydrocolloid amount

\begin{tabular}{|c|c|c|}
\hline \multirow{2}{*}{ Hydrocolloid (\%) } & \multicolumn{2}{|c|}{ HydrocolloidType } \\
\cline { 2 - 3 } & $\mathrm{XG}$ & CMC \\
\hline 0,5 & $0,360 \pm 0,002^{\mathrm{bA}}$ & $0,276 \pm 0,001^{\mathrm{cB}}$ \\
\hline 1 & $0,376 \pm 0,001^{\mathrm{abA}}$ & $0,339 \pm 0,003^{\mathrm{bA}}$ \\
\hline 1,5 & $0,406 \pm 0,003^{\mathrm{aA}}$ & $0,442 \pm 0,011^{\mathrm{aA}}$ \\
\hline
\end{tabular}

Means with different letters in columns (lowercase, indicate comparisons among hydrocolloid amount for hydrocolloid type) and rows (uppercase, indicate comparisons between hydrocolloid type for each hydrocolloid amount) indicate statistically significant difference according to the Tukey test $(\mathrm{p}<0.05)$. 
ticle size of semolina, with the extrusion process and the drying conditions $s^{30}$. ANOVA shows that factors:bran amount, hydrocolloid type and quantity of hydrocolloid and the interactions bran amount ${ }^{*}$ hydrocolloid type and hydrocolloid type ${ }^{\star}$ hydrocolloid amount were significant $(\mathrm{p} \leq 0.05)$.

In Table 10, the results of the interaction bran amount * hydrocolloid type are shown. When using GX or CMC an increase in the bran amount (from $10 \%$ to $30 \%$ ) causes a decrease in the breaking force in raw pasta, this behavior is probably due to the presence of dietary fiber containing cellulose, hemicellulose and lignin, which cause a disruption of the protein-starch matrix ${ }^{25}$. It is typical that inclusion of dietary fiber in products such as bakery can modify textural properties, and in gluten products such as pasta, reduction of flour with gluten by adding flour with high fiber content can cause a lower resistance. Results found by $\underline{25}$ show that textural traits of pasta are affected by type and amount of fiber included in its formulation, finding that increasing the amount of fiber progressively decreased firmness. Equivalent results were reported in gluten-free pastas with addition of hydrocolloids (XG and $\mathrm{CMC})^{27}$.

Interaction type hydrocolloid ${ }^{*}$ hydrocolloid amount for the maximum rupture strength of pastas is detailed in Table 11. When using XG or CMC, an increase in their amount (from $0.5 \%$ to $1.5 \%$ ) causes an increase in the breaking strength, this is possibly because hydrocolloids help to strengthen the network structure of pasta, being necessary the application of a greater force for the rupture of the strand of dry pasta ${ }^{23}$ report a positive correlation between XG concentration and maximum resistance to extension in rice masses incorporated with hydrothermally treated polysaccharide mixtures for preparation of gluten-free noodles. In turn ${ }^{29}$ report that the resistance of pasta including broccoli powder was in the same range of commercial pasta thanks to inclusion of $1 \%$ XG in its formulation.

In general, texture traits of pastas are strictly related to starch source, ingredients used and processing conditions during manufacture. In addition, they are mainly affected by the structural matrix of the network of starches, gluten, additional proteins and other ingredients $s^{28}$.

\section{Conclusions}

Cassava bran addition of in pasta affects color parameters evaluated; decreasing of $L^{\star}$ values. Use of Xanthan gum favors even more luminosity compared to CMC. In addition, there is a tendency toward yellow tonality, a desirable trait in pasta, which increases with the inclusion of bran. Addition of cassava bran in pasta formulation decreases the maximum rupture strength of cooked pasta, elasticity and maximum rupture strength in raw pasta. Use of hydrocolloids, as well as their concentration increase, improves the textural traits evaluated.

\section{Acknowledgements}

To the Government of Sucre and COLCIENCIAS for their financial support throughout the study and development stage of this project. To the University of Sucre and to University of Cordoba for their valuable training.

\section{References}

1. Farias F, Jasko A, Colman T, Pinheiro L, Schnitzler E, Barana A, Demiate I. Characterisation of Cassava Bagasse and Composites Prepared by Blending with LowDensity Polyethylene. Brazilian Archives of Biology and Technology. 2014; 57(6):821-30. https://doi.org/10.1590/ S1516-8913201402506.

2. Teixeira E, Curvelo A, Correa A, Marconcini J, Glenn G, Mattoso L. Properties of thermoplastic starch from cassava bagasse and cassava starch and their blends with poly (lactic acid). Industrial Crops and Products. 2012; 37(1):61-8. https://doi.org/10.1016/j.indcrop.2011.11.036

3. Baiano A, Lamacchia C, Fares C, Terracone C, La Notte E. Cooking behaviour and acceptability of composite pasta made of semolina and toasted or partially defatted soy flour. LWT - Food Science and Technology. 2011; 44:1226-32. https://doi.org/10.1016/j.lwt.2010.11.029

4. Padalino L, Costa C, Conte A, Grazia M, Sillitti C, Bognanni R, Raccuia S, Del Nobile M. The quality of functional whole-meal durum wheat spaghetti as affected by inulin polymerization degree. Carbohydrate Polymers. 2017; 173:84-90. https://doi.org/10.1016/j.carbpol.2017.05.081 PMid:28732922

5. Petitot M, Abecassis J, Micard V. A Review: Structuring of pasta components during processing: impact on starch and protein digestibility and allergenicity. Trends in Food 
Science \& Technology. 2009; 20(11):521-32. https://doi. org/10.1016/j.tifs.2009.06.005

6. Ciccoritti R, Taddei F, Nicoletti I, Gazza L, Corradini D, D’Egidio M, Martini D. Use of bran fractions and debranned kernels for the development of pasta with high nutritional and healthy potential. Food Chemistry. 2017; 225:77-86. https://doi.org/10.1016/j.foodchem.2017.01.005 PMid:28193436

7. Larrosa V, Lorenz G, Zaritzky N, Califano A. Optimization of rheological properties of gluten-free pasta dough using mixture design. Journal of Cereal Science. 2013; 57(3):5206. https://doi.org/10.1016/j.jcs.2013.03.003

8. Mirhosseini H, Rashid N, Amid B, Cheong K, Kazemi M, Zulkurnain M. Effect of partial replacement of corn flour with durian seed flour and pumpkin flour on cooking yield, texture properties, and sensory attributes of gluten free pasta. LWT - Food Science and Technology. 2015; 63(1):184-90. https://doi.org/10.1016/j.lwt.2015.03.078

9. Fiorda F, Soares M, Da Silva F, Grosmann, M, Souto L. Microestructure, texture and colour of gluten-free pasta made with amaranth flour, cassava starch and cassava bagasse. LWT - Food Science and Technology. 2013; 54(1):132-8. https://doi.org/10.1016/j.lwt.2013.04.020

10. Foschia M, Peressini D, Sensidoni A, Brennan M, Brennan C. Mastication or masceration: Does the preparation of sample affect the predictive in vitro glycemic response of pasta? Starch-Starke. 2014; 66(11-12):1096-102. https://doi. org/10.1002/star.201300156

11. Foschia M, Peressini D, Sensidoni A, Brennan A, Brennan C. How combinations of dietary fibres can affect physicochemical characteristics of pasta. LWT - Food Science and Technology. 2015; 61(1):41-6. https://doi.org/10.1016/j. lwt.2014.11.010

12. Carrasquero P. Evaluacion de la calidad de las pastas alimenticias de semola durum. Magister en ciencia y tecnologia de alimentos. Universidad de Zulia. Maracaibo, Venezuela. 2009. PMid:19457067

13. Fiorda F, Junior M, Da Silva F, Souto L, Grossmann M. Farinha de bagaco de mandioca: aproveitamento de subproduto e comparacao com fecula de mandioca. Pesquisa Agropecuaria Tropical (Agricultural Research in the Tropics). 2013; 43(4):10-1590. https://doi.org/10.1590/ S1983-40632013000400005

14. Schulthess A, Matus I, Schwember A. Genotypic and environmental factors and their interactions determine semolina color of elite genotypes of durum wheat (Triticum turgidum L. var. durum) grown in different environments of Chile. Field Crops Research. 2013; 149:234-44. https:// doi.org/10.1016/j.fcr.2013.05.001
15. Chillo S, Ranawana D, Henry C. Effect of two barley $\beta$-glucan concentrates on in vitro glycaemic impact and cooking quality of spaghetti. LWT-Food Science and Technology. 2011; 44(4):940-8. https://doi.org/10.1016/j. lwt.2010.11.022

16. Susanna S, Prabhasankar P. A study on development of Gluten free pasta and its biochemical and immunological validation. LWT - Food Science and Technology. 2013; 50:613-21. https://doi.org/10.1016/j.lwt.2012.07.040

17. Petitot M, Boyer L, Minier C, Micard V. Fortification of pasta with split pea and faba bean flours: Pasta processing and quality evaluation. Food Research International. 2010; 43(2):634-41. https://doi.org/10.1016/j.foodres.2009.07.020

18. Argin S, Kofinas P, Lo Y. Effect of complexation conditions on xanthan-chitosan polyelectrolyte complex gels. Food Hydrocolloids. 2009; 23(1):202-9. https://doi.org/10.1016/j. foodhyd.2007.12.011

19. Mohammadi M, Sadeghnia N, Azizi M, Neyestani T, Mortazavian A. Development of gluten-free flat bread using hydrocolloids: Xanthan and CMC. Journal of Industrial and Engineering Chemistry. 2014; 20(4):1812-8. https:// doi.org/10.1016/j.jiec.2013.08.035

20. Islas A, De la Barca A, Cabrera-Chavez F, Cota-Gastelum A, Beta T. Effect of semolina replacement with a raw: popped amaranth flour blend on cooking quality and texture of pasta. LWT-Food Science and Technology. 2014; 57(1):21722. https://doi.org/10.1016/j.lwt.2014.01.014

21. Fu B, Schlichting L, Pozniak C, Singh A. Pigment loss from semolina to dough: Rapid measurement and relationship with pasta color. Journal of Cereal Science. 2013; 57:560-6. https://doi.org/10.1016/j.jcs.2013.03.007

22. Chillo S, Civica V, Iannetti M, Suriano N, Mastromatteo M, Del Nobile MA. Properties of quinoa and oat spaghetti loaded with carboxymethyl cellulose sodium salt and pregelatinized starch as structuring agents; Carbohydrate Polymers. 2009; 78(4):932-7. https://doi.org/10.1016/j. carbpol.2009.07.013

23. Cai J, Chiang J, Tan M, Saw L, Xu Y, Ngan-Loong M. Physicochemical properties of hydrothermally treated glutinous rice flour and xanthan gum mixture and its application in gluten-free noodles. Journal of Food Engineering. 2016; 186:1-9. https://doi.org/10.1016/j.jfoodeng.2016.03.033

24. Lutfi Z, Nawab A, Alam F, Hasnain A, Haider S. Influence of xanthan, guar, CMC and gum acacia on functional properties of water chestnut (Trapabispinosa) starch. International Journal of Biological Macromolecules. 2017; 103:220-5. https://doi.org/10.1016/j.ijbiomac.2017.05.046. PMid:28506726

25. Tudorica C, Kuri V, Brennan C. Nutritional and physicochemical characteristics of dietary fiber enriched pasta. Journal 
of Agricultural and Food Chemistry. 2002; 50(2):347-56. https://doi.org/10.1021/jf0106953. PMid:11782206

26. Phongthai S, D’Amico S, Schoenlechner R, Homthawornchoo W, Rawdkuen S. Effects of protein enrichment on the properties of rice flour based gluten-free pasta. LWT-Food Science and Technology. 2017; 80:378-85. https://doi. org/10.1016/j.lwt.2017.02.044

27. Romero H, Santra D, Rose D, Zhang Y. Dough rheological properties and texture of gluten-free pasta based on proso millet flour. Journal of Cereal Science. 2017; 74:238-43. https://doi.org/10.1016/j.jcs.2017.02.014

28. Liu T, Hamid N, Kantono K, Pereira L, Farouk M, Knowles S. Effects of meat addition on pasta structure, nutrition and in vitro digestibility. Food Chemistry. 2016; 213:10814. https://doi.org/10.1016/j.foodchem.2016.06.058. PMid:27451161

29. Silva E, Birkenhake M, Scholten E, Sagi L, Van der Linden E. Controlling rheology and structure of sweet potato starch noodles with high broccoli powder content by hydrocolloids. Food Hydrocolloids. 2013; 30(1):42-52. https://doi. org/10.1016/j.foodhyd.2012.05.002

30. Mariotti M, Lametti S, Cappa C, Rasmussen P, Lucisano M. Characterisation of gluten-free pasta through conventional and innovative methods: evaluation of the uncooked products. Journal of Cereal Science. 2011; 53(3):319-27. https:// doi.org/10.1016/j.jcs.2011.02.001 